\title{
A DOCÊNCIA NO ENSINO FUNDAMENTAL I: DESAFIOS E POSSIBILIDADES
}

Viviane Barrozo Manfré, Michele da Silva Carlos, Onaide Schwartz Mendonça

Universidade Estadual Paulista - UNESP, Curso de Pedagogia do Departamento de Educação, Presidente Prudente, SP. E-mail: vivianemanfre12@gmail.com

\section{RESUMO}

Este trabalho tem como objetivo refletir sobre a relação teoria-prática em sala de aula e compreender o que é ser professor de Ensino Fundamental I, os desafios e as possibilidades da docência nessa etapa da Educação Básica. Como objetivos específicos pretende-se: observar a relação professor - aluno; identificar e analisar como as sete áreas que compõem o currículo são trabalhadas; observar e analisar as metodologias utilizadas nas práticas educativas, bem como as atividades propostas pelo professor. Considerando os objetivos deste estudo desenvolveremos a abordagem da pesquisa qualitativa, e usaremos pesquisa bibliográfica em material teórico com o intuito de realizar levantamento de informações e análise sobre o que é ser professor do Ensino Fundamental I e quais são os saberes necessários para ser docente de Ensino Fundamental I.

Palavras-Chave: Estágio Supervisionado; Docência; Ensino Fundamental I; Polivalência; Interdisciplinaridade.

\section{TEACHING IN FUNDAMENTAL TEACHING I: CHALLENGES AND POSSIBILITIES}

\begin{abstract}
The main objective of this work is to reflect on the theory-practice relationship in the classroom and to understand what it is to be a primary school teacher, the challenges and possibilities of teaching in this stage of Basic Education. Specific objectives are: to observe the teacher-student relationship; identify and analyze how the seven areas that make up the curriculum are worked out; observe and analyze the methodologies used in the educational practices, as well as the activities proposed by the teacher. Considering the objectives of this study, we will develop a qualitative research approach, and will use bibliographic research in theoretical material with the intention of conducting a survey of information and analysis about what it is to be a teacher of Elementary School I and what are the necessary knowledge to be teaching teacher Fundamental I. Keywords: Supervised internship; Teaching; Elementary School I; Multifunctionality; Interdisciplinarity.
\end{abstract}




\section{INTRODUÇÃO}

O presente texto é fruto das reflexões realizadas durante as aulas da disciplina de Estágio Supervisionado de Anos Iniciais do Ensino Fundamental II e das observações e experiências vivenciadas durante o estágio supervisionado, realizado por nós, graduandas do quarto ano do curso de Licenciatura em Pedagogia, pela Faculdade de Ciências e Tecnologia (FCT/UNESP Presidente Prudente).

O estágio foi realizado em uma escola municipal de Presidente Prudente, interior de São Paulo, situada na zona norte, periférica, em um distrito caracterizado por abrigar uma população considerada de classe média - baixa, sendo a mão de obra local bastante diversificada e não qualificada. Atualmente, estão matriculadas 144 crianças na Educação Infantil e 145 nos Anos Iniciais do Ensino Fundamental I.

O presente estudo está centrado nas seguintes questões: $O$ que é ser professor do Ensino Fundamental I? Quais são os saberes necessários para ser docente de Ensino Fundamental I? Tentando responder essas questões apresentaremos aqui uma breve reflexão.

O interesse pelo tema surgiu durante as observações no estágio obrigatório, pois verificouse que docentes ministram diferentes disciplinas que compõem o currículo. Assim, surgiram dúvidas como: é possível ministrar diferentes disciplinas e ser didático? Ainda, o professor de Ensino Fundamental I precisa ter uma grande bagagem de conhecimento e ainda atender às demandas e os desafios que surgem no decorrer das aulas.

O objetivo geral deste trabalho consiste em refletir sobre a relação teoria-prática em sala de aula, em compreender o que é ser professor de Ensino Fundamental I, os desafios e as possibilidades da docência nessa etapa da Educação Básica.

Como objetivos específicos pretende-se: observar a relação professor - aluno; identificar e analisar como as sete áreas que compõem o currículo são trabalhadas; observar e analisar as metodologias utilizadas nas práticas educativas, bem como as atividades propostas pelo professor.

\section{METODOLOGIA}

A abordagem metodológica adotada nesse trabalho é de pesquisa qualitativa, devido à natureza do objeto de estudo. Nessa pesquisa, o processo de coleta de dados envolveu observações das práticas pedagógicas desenvolvidas pelas professoras regentes da unidade escolar durante a vivência no estágio obrigatório.

\footnotetext{
A pesquisa qualitativa tem o ambiente natural como fonte direta dos dados e o pesquisador como instrumento - chave. [...] A pesquisa qualitativa é descritiva. [...] 0 significado é a preocupação essencial na abordagem qualitativa. [...] Na rota ao realizar uma investigação. Isto é, existe uma escolha de um assunto ou problema, uma coleta e análise das informações. [...] As informações que se recolhem, geralmente, são interpretadas e isto pode originar a exigência de novas buscas de dados. (TRIVIÑOS, 1987, p. 128-131).
}

Em consonância com TRIVIÑOS (1987), a riqueza da pesquisa qualitativa consiste no fato de que, considerando os objetivos a serem alcançados, se investigará o movimento das pessoas e analisará o contexto no qual elas encontram-se inseridas, visto que em casos de pesquisas que envolvem sujeitos, a sua compreensão recebe influência do contexto em que se encontra. Assim, a ênfase nesta abordagem metodológica não recai somente sobre o resultado, mas sobre todo o processo.

Nesse âmbito, optamos pela pesquisa do tipo bibliográfica em material teórico, tornando possível o levantamento de informações e análise sobre o que é ser professor do Ensino Fundamental I e quais são os saberes necessários para ser docente de Ensino Fundamental I. Os dados levantados serão analisados conforme os preceitos da pesquisa qualitativa. 


\section{RESULTADOS}

Uma das salas onde foi realizado o estágio supervisionado foi uma turma do quarto ano, composta por 10 meninas e 08 meninos, sendo notório o bom relacionamento entre as crianças e a professora regente. A segunda sala observada foi uma turma do terceiro ano. Ao todo, encontravam-se matriculados 24alunos, com uma heterogeneidade de meninos e meninas.

De modo geral, em ambas as salas, as crianças participam das atividades demonstrando interesse e são bem comunicativas. No entanto, percebe-se que nas turmas existem níveis de conhecimentos diversos, uma vez que alguns alunos precisam ser estimulados para desenvolver as atividades enquanto outros ficam dispersos. Em alguns momentos precisam ser chamados à atenção.

Durante o estágio percebemos que, muitas vezes, os professores acabam priorizando no desenvolvimento do trabalho pedagógico apenas duas disciplinas em detrimento das demais: português e matemática. As turmas possuem uma rotina escolar, na qual encontram-se organizadas / distribuídas as disciplinas conforme os dias da semana e os horários de aula. Isso significa dizer que, no planejamento da rotina escolar, está prevista para cada disciplina uma carga horária de aula. Porém, nas duas salas observadas percebemos a ênfase apenas nas disciplinas de português e matemática, visto que algumas vezes os horários de aula destinados às demais disciplinas acabaram sendo utilizados para o ensino desses conteúdos. A professora regente do terceiro ano, em determinada ocasião, afirmou que estava consciente de que ao trabalhar português e matemática estava garantindo a polivalência, já que a base do conhecimento perpassa pelo aspecto do domínio da leitura, escrita e cálculo.

Essa é uma forma equivocada de entender a polivalência, pois todas as disciplinas são importantes e precisam ser trabalhadas. Isso requer deste profissional da educação uma grande bagagem de conhecimentos científicos e, mais que isso, saber construir com as crianças estes conhecimentos para que aprendam de forma significativa, ou seja, saber mediar, pois se a criança não tiver uma mediação ela possivelmente encontrará dificuldades para aprender.

Verificamos, ainda, a ausência de interdisciplinaridade no decorrer das aulas em ambas as salas observadas. As disciplinas são apresentadas aos discentes de forma fragmentada, assim como consta na rotina escolar. Isso significa dizer que, cada conhecimento é trabalhado em determinada disciplina, sem articulá-lo às demais áreas do conhecimento. No momento em que se encerra a hora/aula de determinada disciplina encerram-se, também, os conteúdos, sendo que esses têm continuidade nas próximas aulas.

Entretanto, acredita-se que se as professoras regentes conseguissem desenvolver as práticas educativas de modo interdisciplinar seria muito enriquecedor para os educandos, haja vista que, além de perceber a relevância dos conhecimentos em seu dia-a-dia, também aprenderiam várias áreas do conhecimento em conjunto, de forma articulada, assegurando aprendizagens significativas.

\section{DISCUSSÃO}

Antes de iniciar a reflexão sobre o que é ser professor do Ensino Fundamental I, precisamos compreender o que significa ser professor/educador, quais suas especificidades e atribuições.

Conforme Moran (2007, p. 74):

O educador é especialista em conhecimento, em aprendizagem. Como especialista, espera-se que ao longo dos anos aprenda a ser um profissional equilibrado, experiente, evoluído; que construa sua identidade pacientemente, integrando o intelectual, o emocional, o ético, o pedagógico.

Assim, compreende-se que o educador é um profissional da educação que requer uma série de qualidades, dentre elas encontra-se a questão da aprendizagem do profissional a partir de sua formação inicial e continuada, o desenvolvimento de estratégias para que o outro (no caso, o 
educando) The compreenda e, também, compreender o outro no processo de ensino e aprendizagem.

Moran (2007) define cinco etapas essenciais à aprendizagem de ser educador: a "iniciação" que se refere aos primeiros anos de atuação do profissional, recém formado. Essa etapa acontece, frequentemente, quando o professor é chamado para substituir seus pares. Ao mesmo tempo em que procura ser inovador, reproduz em suas práticas algumas estratégias de seus professores, vivenciadas como aluno. Em síntese, trata-se de uma etapa de insegurança, entusiasmo, de medo de não conseguir e fracassar, mas, também, de aprendizagem. Com o decorrer do tempo, desenvolve a percepção de que cada turma é diferente e tem suas especificidades. Aos poucos ganha confiança e segurança no que faz, o medo de fracassar gradativamente vai cedendo lugar para o "arriscar mais".

A segunda etapa consiste na "consolidação", momento em que o professor, dia após dia, vai consolidando seu modo de ensinar, de relacionar-se com os discentes. Neste momento tem um domínio maior do processo de ensino e aprendizagem. Amplia o número de aulas, de turmas, possui segurança e calma, mas, não raras vezes, repete seus métodos, estratégias e recursos no desenvolvimento do trabalho pedagógico.

Na sequência, passa pela etapa da "crise da identidade", caracterizada pelo cansaço, em que dar aula vai se tornando massacrante, insuportável, repetitivo. São inúmeros os fatores que influenciam essa crise, dentre eles pode-se mencionar a desvalorização da docência, salário baixo, condições precárias para dar aula. "Qualquer motivo justifica não dar aula... Muitas vezes essa crise profissional vem acompanhada de uma crise afetiva". (MORAN, 2007, p. 76).

A etapa mencionada anteriormente foi identificada em alguns momentos durante o estágio, tendo em vista que, não raras vezes, nós discentes do curso de Licenciatura em Pedagogia, ouvimos relatos de professores que evidenciaram a "crise da identidade", o cansaço, o desânimo em dar aulas, com afirmações como: "vai vendo o que te espera", "pensa bem se é isso que você quer, porque ainda dá tempo de escolher outra profissão", "ser professor é muito desgastante, ainda mais em nosso contexto atual", dentre outros comentários negativos. É importante ressaltar que tais comentários foram frequentes ao longo de nossas vivências nos estágios.

Em seguida, vem a fase da "mudança". A partir da crise profissional, alguns educadores buscam refletir sobre sua carreira profissional e pessoal. Buscam saídas, encontrar caminhos que os levem a reaprender e aprender coisas novas, ou seja, buscam se atualizar, passam a observar mais atentamente, conversam e refletem. Isso acaba culminando em um profissional mais "[...] humano, acolhedor, compreensivo, tolerante, aberto. Dialogam mais, ouvem mais, prestam mais atenção". (MORAN, 2007, p. 76).

Por último, e não menos importante, é a etapa do "educador bem sucedido", caracterizada pelo sucesso profissional, neste caso, pelo sucesso pedagógico.

Com base nas leituras realizadas e observações no campo de estágio, constatamos que ser professor do Ensino Fundamental I significa ter a capacidade de ministrar e dominar as sete áreas do conhecimento, o que significa dizer que é ser professor polivalente, haja vista que para ser polivalente é fundamental o domínio dos conteúdos e, também, saber transmiti-los.

Segundo Cruz (2012, p. 135):

Polivalência da docência nas séries iniciais foi construída historicamente mediante a organização da escola básica e que apresenta como exigência funcional legal para o/a professor/a a incumbência de lecionar em todas as áreas de conhecimento, estabelecidas pelo currículo, já desde a sua formação inicial.

A polivalência é importante para o professor, uma vez que consegue articular um conhecimento com o outro e, embora seja difícil para ele ser polivalente, isso pode ser um ganho muito grande e enriquecedor para o aluno. Ou seja, ser polivalente é um enorme desafio para o 
professor dos Anos Iniciais, pois pressupõe que ele trabalhe com todas as áreas do conhecimento, de modo que os alunos compreendam, assegurando uma aprendizagem significativa.

Nessa perspectiva Cruz e Neto (2013, p. 61) afirmam que

[...] a profissionalidade docente é instituída numa dinâmica de interação entre os elementos de regulação social da profissão e as formas subjetivas do sujeito que se faz professor, implicando, nesse contexto, uma forma particular do professor polivalente de relacionar os conhecimentos das disciplinas de referência e os conhecimentos didáticos pedagógicos. Relação que os sujeitos estabelecem em suas práticas com as demandas sociais internas e externas à escola expressando-se em modos próprios de ser e atuar como docente, e que, ao lidar com a polivalência, estariam imbricadas na ação docente dimensões outras que vão além da legitimidade do conhecimento científico.

Na construção do sujeito professor há uma série de instâncias pelas quais ele perpassa, tais como: o que a sociedade pensa, o que a escola pensa, o que os pais pensam. Passa também pelos conhecimentos científicos e pela polivalência e, a partir disso, é fundamental desenvolver a sensibilidade de atender às necessidades dos alunos de acordo com os seus conhecimentos, articulando o que sou e com quem estou. Ou seja, é o protagonismo do professor que torna o aluno protagonista.

De acordo com Cruz e Neto (2013, p. 60):

[...] a particularidade daquele profissional em atender à fase inicial de escolarização, a identificação com a fase de desenvolvimento da infância atrelada à oportunidade de acompanhar mais de perto as aprendizagens dos discentes parecem ser aspectos que ganham relevância na configuração da profissionalidade polivalente.

É importante ressaltar que polivalência não é sinônimo de interdisciplinaridade, visto que a polivalência está ligada aos conhecimentos, é o saber, enquanto que a interdisciplinaridade é unir todas essas coisas. $O$ professor pode ser polivalente e através da sua polivalência trabalhar de forma interdisciplinar, interligando todas as áreas do conhecimento que compõem o currículo como, por exemplo, a partir do desenvolvimento de projetos em torno de um tema pertinente para a formação do educando.

Assim, consideramos que a profissionalidade docente polivalente é produto e processo de um conjunto de ações, representações e relações que o/a professor/a desenvolve na constituição da sua profissão, produzindo na interface entre as demandas de regulação da sua atuação profissional e as formas subjetivas do sujeito que se faz professor. (CRUZ; NETO, 2013, p. 68).

Dessa forma, a polivalência está associada não a um aspecto específico, mas a um conjunto de ações do docente. Dentre os aspectos positivos da polivalência encontra-se o fato de permitir ao professor uma visão global de seus discentes, ou seja, o professor passa a conhecer o aluno em sua singularidade, a identificar a área do conhecimento em que eles possuem mais afinidades e, também, identificar as áreas em que eles apresentam mais dificuldades de modo que, a partir deste conhecimento, o professor atenda às necessidades de aprendizagem de seus educandos e explorem suas potencialidades, sempre buscando desenvolver um processo de ensino e aprendizagem motivador e prazeroso. Por lidar com a fase inicial dos discentes no processo de escolarização, visando à formação humana, cidadã e crítica dos educandos, cabe ao professor polivalente assumir o compromisso de ampliar as oportunidades de aprendizagens significativas.

\section{CONCLUSÃO}

Neste texto procuramos discutir e refletir sobre o que é ser professor no Ensino Fundamental Idiscorrendo sobre suas especificidades e atribuições.

Com base nos autores consultados, compreendemos que dominar os conhecimentos científicos é fundamental, mas o mais importante é conseguir assegurar a compreensão e a 
aprendizagem das crianças sobre esses conteúdos. Por ser a polivalência uma das características do docente dos Anos Iniciais é fundamental que esteja sempre buscando novos conhecimentos, o que significa dizer que não basta somente a formação inicial, é preciso ir em busca de formações continuadas.

Diante disso, o professor precisa compreender o ensino como um ato intencional que visa o desenvolvimento integral dos alunos, uma vez que não deve se pautar apenas no desenvolvimento cognitivo, ele precisa pensar em diversificados recursos que o ajudarão a trabalhar os conteúdos do currículo, estimulando as diferentes vias sensoriais dos alunos, fazendo o uso de diferentes linguagens para garantir o processo de ensino e aprendizagem, poiso foco do processo de ensino e aprendizagem deve ser o aluno. Portanto, a formação desse aluno deve garantir o desenvolvimento da capacidade de aprender.

Embora a polivalência seja uma das características do professor de Ensino Fundamental I, constatamos em nossas experiências durante o estágio que, as docentes não tinham total clareza sobre o que seria polivalência. No que se refere à interdisciplinaridade, identificamos que ela não se efetiva nas práticas docentes, talvez pela dificuldade de exigir mais tempo e compromisso no desenvolvimento dos planejamentos, buscando realizar projetos, visando partir de um tema e articulá-lo com as demais áreas do conhecimento.

Afinal, concluímos que o professor polivalente exerce um papel extremamente importante na formação das crianças, já que trabalha coma fase inicial de formação humana, cidadã e crítica delas e, por ter de lidar com todas as disciplinas, precisa garantir as oportunidades de aprendizagem aos seus alunos, sem priorizar algumas disciplinas em detrimento de outras.

\section{REFERÊNCIAS}

CRUZ, S. P. S; NETO, J. B. A construção da profissionalidade polivalente na docência nos anos iniciais do ensino fundamental: refletindo sobre elementos estruturantes. Revista Educação e Emancipação, São Luís/MA, v. 6, n. 1, jan./jun. 2013.

CRUZ, S. P. S. Profissionalidade polivalente e o trabalho docente nos anos iniciais do ensino fundamental.Debates em educação. Maceió, v. 4, no 7, p. 133-151, Jan./Jul. 2012.

MORAN, J. M. A aprendizagem de ser educador. In: A educação que desejamos: Novos desafios e como chegar lá. São Paulo: Papirus, 2007, p. 74-81.

TRIVINOS, A. N. S. Introdução à pesquisa em ciências sociais: a pesquisa qualitativa em educação. São Paulo: Atlas, 1987, p. 116-133. 